\title{
The Role of Buddhism in Environmental Protection and Sustainable Development in Vietnam Today
}

\author{
Assoc. Prof. Pham Cong Nhat* \\ University of Social Sciences and Humanities, VNU, Vietnam \\ *Corresponding Author: Assoc. Prof. Pham Cong Nhat, University of Social Sciences and Humanities, \\ VNU, Vietnam

\begin{abstract}
Environmental protection and sustainable development are the common development trend of many countries in the world today including Vietnam. The career of protecting the environment towards sustainable development requires the joining of many different forces in society, including religions. As one of the religions tends to incarnate, Buddhism in the past as well as the present always focused on environmental protection and sustainable development. That, not only manifests itself in the way of action but also expresses clearly with philosophical views in the Buddhist teaching system. Vietnamese Buddhism always accompanies and develops with the nation. In today's innovation career, the contribution of Buddhism to environmental protection and sustainable development is one of the important contributions of this religion in the cause of innovation and development in Vietnam today. This article is based on the analysis of the views of Buddhist philosophy on the environment and the development and contributions of Vietnamese Buddhism in history to come to analyze and propose solutions to promote more and the role of Buddhism in the current environmental protection and sustainable development in Vietnam.
\end{abstract}

Keywords: Buddhism, the System of Doctrine, Invading Life, Environmental Protection, Sustainable Development

\section{INTRODUCTION}

In the development process, besides the great achievements, humanity is also facing many risks and challenges, including the risk and challenges of environmental degradation. Therefore, protecting environment effectively and towards sustainable development is one of the most important goals of each country as well as all humanity has been posed and actively looking for solution. Of course, the issue of environmental protection and sustainable development is not until now but the humanity has been set up very early in the history of human thought with many different ways of expression in it there are religions. As one of the religions tends to incarnate, In its teaching system Buddhism is always regarded as one of the leading religions in proposing ideas about environmental protection and sustainable development. These thoughts are not only found in the teachings of Buddhism, but also in the system of rituals and methods of daily practice of this religion. Studying philosophical ideas about environmental protection and sustainable development in Buddhist philosophy is of great importance not only in theory but also in practice, especially in enhancing the role of Buddhism. in the career of environmental protection and sustainable development in Vietnam today.

\section{METHODS}

There are two groups of methods we use in this article. Firstly, a group of general research methods such as analyzing, synthesizing and searching documents were used to analyze and clarify the theoretical bases of environmental protection and sustainable development viewpoint in system of Buddhist philosophical thought. And secondly, group of interdisciplinary approaches such as statistics, comparison and use of sociological survey results (secondary data) to analyze and describe the role of Buddhism in the protection career. Environment and sustainable development in Vietnam today.

\section{Results}

\subsection{Environmental Protection and Sustainable Development}

The environment with the most common meaning includes all factors of infertility and biology, nature and society that have an impact, directly or indirectly affecting human health and life. Human life 
whether in the early period or even in the modern development period depends very much on the surrounding environment. Currently, humanity is facing many challenges when the environment is degraded or degraded environment. Environmental degradation is a change in the quality and quantity of environmental components, adversely affecting human and natural life, destroying ecosystems and extinction of wildlife. In particular, the environmental component is understood as the elements that make up the environment: air, water, land, sound, light, underground, mountains, forests, rivers, lakes, sea creatures, ecosystems (Johnson, D.L., S.H. Ambrose, T.J. Bassett, M.L. Bowen, D.E. Crummey, J.S. Isaacson, D.N. Johnson, P. Lamb, M. Saul, and A.E. Winter-Nelson, 1997; pp.581-589). Environmental degradation is one of ten official threats that have been warned by The UN: "Decreasing the capacity of the environment to meet social and ecological goals and needs" [The International Strategy for Disaster Reduction, 2004]. These are threats that are not only potential but increasingly existential but many countries have been suffering from negative impacts due to environmental degradation, which is extremely heavy. Therefore, protecting the environment, keeping the environment always clean is always the duty and responsibility of every resident living on the globe. Environmental protection is a natural environmental protection practice on individual, controlled or government levels, for the benefit of both the environment and people. Current environmental protection principles include:

- Environmental protection is the responsibility and obligation of all agencies, organizations, households and individuals;

- Environmental protection in harmony with economic development, social security, ensuring children's rights, promoting gender and development, biodiversity conservation, responding to climate change to protect ensuring everyone to live in a clean environment;

- Environmental protection must be based on the rational use of resources and waste reduction;

- National environmental protection associated with regional and global environmental protection; environmental protection to ensure no harm to national sovereignty and security;

- Environmental protection must be in accordance with the law, natural, cultural and historical characteristics, the level of socio-economic development of the country;

- Environmental protection activities must be regularly carried out and prioritized to prevent environmental pollution, incidents and degradation;

- Organizations, households and individuals that use environmental components and benefit from the environment are obliged to contribute financially to environmental protection;

- Organizations, households and individuals causing environmental pollution, incidents and degradation must overcome, compensate for damage and other responsibilities as prescribed by law.

At the same time, the main contents of the current environmental protection work include:

- Prevention of degradation, pollution and environmental incidents;

- Overcoming degradation, pollution and environmental incidents, and...

- Responding to climate change (Law of Environmental Protection; 2014).

The current environmental protection is not purely to affect the surrounding environment (even if this is true, it is difficult to implement) but also actively interacting to create a sustainable environment or Sustainable Development Process. Sustainable development is not just a new concept that defines a development in all aspects of current society, but must ensure continued development in the future. This concept is now the target of many countries in the world. Each country will rely on its own economic, social, political, geographical, cultural ... characteristics to plan the strategy that best suits that country. The concept of sustainable development appeared in the world for the first time in the 1970s of the twentieth century. By 1980, in the "World Conservation Strategy" developed by the International Union for Conservation of Nature and Natural Resources (IUCN), the first definition of sustainable development was given. Accordingly, sustainable development is defined as "the development that meets the needs of the present without hurting the ability to meet the needs of future generations", is "the whole approach. face and time processes lead us to the final point of 
sustainability" (Shaker, R.R., 2015, p.305). This concept mainly emphasizes the aspect of effective use of natural resources and ensuring the living environment for people in the development process.

In principle, sustainable development is the process of simultaneously operating three development areas: sustainable economic growth, prosperous society, fairness, stability, diverse culture and a healthy environment. resources are sustained. Therefore, the system completes the ethical principles for sustainable development, including the principles of sustainable development in both "three-leg": economic, social, environmental.. Currently, the concept of sustainable development on an international level has a common unity and a goal to implement sustainable development into the millennium goal. The content of sustainable development has been unified in three aspects: sustainable economic development, sustainable development of society and environmentally sustainable development (Pham Thi Thanh Binh, 2016).

\subsection{Thought of Buddhist Philosophy on Environmental Protection and Sustainable Development}

In its teaching system, although Buddhism does not use terms like "environmental protection" or "sustainable development" ... but, philosophical viewpoints about the relationship between people and nature; on the policy of exhorting disciples, disciples and all beings in the world to make a harmonious, natural-friendly lifestyle as one of the endings to perform "liberation" showed Buddha The teacher was interested in issues such as environmental protection and sustainable development very early. This is reflected in the major treatises of Buddhism, such as: The theory of causation (Thuyết Duyên khởi), Equal theory for all things (thuyết Vạn vật bình đẳng) and Causal - Repaid Theory (thuyết Nhân quả - Báo úng).

The theory of causation (pratītyasamutpāda) also called: The twelve links of "Cause and effect" or "Karmic causality" in "The four noble truths" (in the "Four Noble Truths", four truths of Buddhism), is the basic reasoning system of Buddhism that expresses insight into the universe and humanity. The concept of "theory of causation" comes from the view of the Buddha saying: the world, the universe is a unified whole by overlapping, tightly divided relationships. This is predestined affinity (Pratyaya, duyên) let that exist, everything in this world therefore exists in a diverse and vivid way. If one thing is unfortunately lost, it will lead to the loss or alteration or disturbance of another... Thus, the relationship between people and nature is a symbiotic relationship, with survival and development. If unfortunately one party is depressed then all are affected. The world of all things is diverse and abundant, but all exist in the relationship of mutual support and mutual effects. Their existence is both the cause of each other but also the result of each other. Each thing and phenomenon exists in the world due to certain causes or conditions.

In Samyuktagama sutra (Samyuktāgama), volume 10 of Buddhism has illustrated the ideology of causation, said:"If this is, the other is, because of this being, the other being, if this is not there, that one is not there, because of this destruction, the other kills ..." (Thich Minh Chau, 2015). Everything is created by causation. Causation is both the starting point is both the end point of "liberation" (Moksha)... But the most important thing in causation is to express existence in the human-social and natural dependency relationship. From The theory of Causation origination can see individuals, humanity, society can not exist independently, but exists in a relationship closely related to nature. When we hurt nature, it is when we hurt humanity itself. When we sabotage nature is when we undermine the existence of humanity itself. Since then, Buddhism draws the necessary instructions for sentient beings: "How to prevent ecological destruction caused by humans, how to maintain and protect the normal ecological balance, how to improve the correlation conditions, beneficial factors to enhance ecology, is human's most important responsibility, is also the most important responsibility for humanity to protect itself' (Phương Lập Thiên, 2005).

Equal theory for all things. Born in the context of ancient Indian society, a society that is divided into different levels is extremely strict, so Buddhism as well as many religions in India now emphasize the equal relationship between people and society. However, Buddhism has gone further in terms of conception than other religions in that it not only affirms the equal relationship between people and people in society but also the relationship of this equality is open. wide for all things in the world. Buddhism asserts: the existence of all things in this world is in a unified form. In this world, everything that exists has the same equality: not being, not being, not high, not low. However, due to the different "karmic", each object is transformed into "reincarnation" into different "lifetimes" (a form that exists differently from the previous existence). Life of every thing, phenomenon in every 
"life" (including life in human life) is always temporary, sometimes or like the wind blowing, flying clouds...In the rotation of creation, everything transforms both the cause of each other and the result of each other according to the rules of reincarnation: "Sinh - Trụ - Dị - Diệt" or: "Thành - Trụ - Hoại - Không", so everything in high position or low position becomes necessary for each other's existence. The role and position of each thing, a life in this world thus becomes equal, not high, not low, not good, not mean. Buddha said: "Everyone in those hundred different races can bring bath powder to water and wash it, except to remove the dirty structures so it can be cleaned. . . all of those hundred different races can use any kind of wood as a fire, then use a puncher to make fire and fire grow" (Kinh Trung A Ham sutra, Pham Chi A Kinh sutra, 1992; p.202). And Namennais ${ }^{1}$ wrote: "Creator does not give birth to anyone, who is a coward, who is a teacher, a servant, who is a king, who is I?" Creator creates all equal people"(Kinh Trung A Ham sutra, Pham Chi A Kinh sutra, 1992; p.107) Since then, Buddhism advised sentient beings to practice a compassionate, non-competitive way of life and to harm the surrounding environment, a lifestyle of good and non-killing is also derived from the philosophy of all things equally as assigned above.

Causal - Repaid Theory. This is one of the basic theories of Buddhist philosophy of human life. Causal - Repaid Theory derives from one of the contents of the Four Noble Truths of Buddhism indepth analysis of the causal relationship in the cycle of reincarnation of all things. According to Buddhism, all things that form, exist, develop and transform (Samsara) have their causes. The cause is what creates results. But each cause can produce many results depending on certain conditions (It is up to "pratyaya"). The Hetu-pratyaya-Repaid rule is an objective law in the world of things including humans. Also according to Buddhism, the life of every human being from birth to maturity and loss is a "predestined". That predestined is not a coincidence but an inevitable result of the effects of the law of cause and effect (also called karma). each person's karma in life can be "bad karma" (life has many uncertainties, less safety) or "good karma"(life has many advantages and benefits). People create their own "karma" but the effects of karma (or karmic retribution) each person's impact on real life is quite complicated, sometimes directly, sometimes indirectly. For example, this life creates "karma" but it is very possible that "karma" shows results and impacts on the next life. Simply put, "Causal - repaid" is to do good things, you will receive good "retribution", while doing evil, you will receive an evil "retribution". The law of "cause and effect" is the method, the rule and the fixed law of causation, it is fulfilled for anyone who does not mention intimate, rich or poor. Therefore, Buddhism advises living in life to be responsible in every thought, word and action. If each of us does not believe in the law of "cause and effect", then we will live emotionally, irresponsibly, only greedily selfish to hurt others. However, in fact, according to causal Buddhism, good and bad karma will come sooner or later, depending on the condition, but if living in life, each of our words or deeds can be created accidentally or intentionally career. Having "karma" of course will produce "karmic retribution". Let each of us be afraid of bad retribution in this life, stay away from sinful things, do good deeds for human love in life to get good karma in the future. A good person does not harm anyone, a family is perfect in moral character, society will develop stably in a sustainable and long-term way.

From the above basic philosophical treatises, Buddhism sets out basic ethical principles to implement a friendly, sociable lifestyle with the environment, environmental protection and towards sustainable development such as:

First, the principle of implementing environmentally friendly lifestyles and upholding ethical and non-killing ethical standards. Must take a hospitable and friendly lifestyle with all species in lieu of selfish, self-pervading lifestyle, as Buddha often teaches: "Buddhists should not either kill themselves, or tell the killers, use the means of killing, praising the killing, seeing killing but depending on the wedding, the ring comes to use the charm to kill, and so on, all the beings have no life, they will not intentionally kill them" (https://thuvienhoasen.org, 2010). Or: "Often the mind is murdered, the more the karma grows, the more it spins in the samsara, there is no day to leave" (Lankavatara sutra) (http://daibaothapmandalataythien.org, 2016).

Greed is one of "three poisons" (tam độc), it mean: greed, anger and ignorrance (tham, sân, si) according to the Buddhist concept. Three poisons harm the spiritual health of people. Once the greed is overwhelmed, leading the way will leave very serious consequences. Buddhism has taught people to live: "thiểu dục tri túc" (want less, know enough). "Thiểu dục tri túc", it teaches people to

${ }^{1}$ Priests, philosophers, French political theorists (1782-1854) 
understand and value what they have. It should not be because of greed, harming all species in nature, breaking the inherent order of nature. It is a way of life, the motto of living completely in line with the present age. It is a way of life full of knowledge, there is no place for self-respect, not for your own benefit but harming the environment, to nature and all species. It is a way of knowing how to use natural resources reasonably, reducing the pressure on the environment, avoiding the waste of using natural resources, or relying on nature. Being aware of this, people will not over-exploit naturally, not pollute the environment, live in harmony with nature, exploit naturally at an appropriate level so that nature has time to regenerate. It is also a way of life responsible for oneself, the future of future generations so that they can continue to enjoy and exploit nature to serve their lives (Nguyen Thi Trang, 2017).

Second, arouse Buddha count, stay away from dosa (sân hận). In order to do so, each person has no other way but to take tolerance with unconditional love between himself and all species as salvation, just like the Buddha used to tell his disciples: "There is no reason to be friendly with this person and hostile to others. Everyone is equal, because everyone wants to enjoy peaceful happiness and no one likes sickness and suffering. Therefore, we must treat people with irrespective of love" (Joanthan Landaw, 2006; p. 167). With Buddhism, all things in the world (not only in humans) have the right to exist equally, regardless of high and low, to be mean. However, due to differences in characteristics, shape as well as content structure and mode of operation, there is inevitable conflict of interests. The peak of the conflict can create conflicts between the parties. Therefore, the best way to resolve conflicts and resolve conflicts is to arouse Buddha nature, stay away from dosa (sân hận), taking reconciliation, giving way to each other instead of bigotry and competition and consider it as one of the basic moral standards of sentient beings on the path to seeking "mokșa" for themselves and the community. Therefore, the opening of compassion and love of all species, regardless of being high and low, regardless of luxury or humility, must become one of the basic standards of ecological ethics that every sentient being needs to be self-conscious perform, same as the Buddha's teaching in Karuna sutra: "...Bring joy to all beings; May they all be at peace; Do not miss any friendship; sick or healthy people; Large or tall varieties; Medium or short body, small, rough; There is a general appearance or no appearance; Be near me or in a remote place; Already born or about to be born; May all be at peace ..." (Nguyen Thi Trang, 2017). Arouse Buddha count, stay away from dosa (sân hận) in each person has thus become one of the important moral principles of Buddhism in the awareness and conduct of the relationship between people and people. with the natural world.

Third, create good kamma, stay away from bad kamma. The idea of "creating good kamma, stay away from bad" is one of the popular ecological ethical principles of Buddhism to practice a friendly lifestyle of sentient beings on the path of cessation of suffering. There are many ways to "create good kamma, stay away from bad", but in Buddhism the best way is to do "ten good deeds" (sa. daśakuśalakarmāṇi) and "five precepts" (panca veramani). "Ten good deeds" are 10 good deeds done through actions (body), words (speech) and thoughts (thoughts). There are 3 rules for action (body) including: No killing, no thief and no sexual misconduct; 4 rules for speech (mouth) include: Do not lie, do not speak double country (say two-way), do not speak monotony and do not speak frivolous; 3 rules for thinking (mind) include: no thoughts of desire (no desire), no anger, sadness and no delusion. Five precepts are the five undocumented commandments of the monks at home, and Buddhists pray to receive these five precepts (Precepts: is a barrier that prevents bad things of body, mouth, thoughts). Five precepts include: No killing, no stealing, no sexual misconduct, no drinking, no ambition (no talking, indiscriminately).

Fourth, realizing life is anatta, impermanence. Buddhism believes that once we realize that life is anatta, impermanence, it also helps us to change our purpose, lifestyle and moral standards in life. Instead of pursuing a self-centered, selfish goal and lifestyle, for each of us we will voluntarily choose a life of selflessness, dedication to the community, for our fellow human beings. In this way of life, all traditional ethical principles and norms will be condemned and replaced by new ethical principles and standards - the ethics of a sustainable community lifestyle or ethics in environmental protection and sustainable development (Pham Cong Nhat, 2017; pp.1-9).

\subsection{Vietnamese Buddhism in the Cause of Environmental Protection and Sustainable Development Today}

Vietnam is a developing country. Over the past years, along with the policy of innovation and 
international integration, Vietnam's socio-economic life has changed rapidly in many fields, thereby creating positive impacts on the quality. the amount of life of every Vietnamese citizen. However, like many developing countries in the world, in the process of development, Vietnam is confronted with many challenges including environmental protection and sustainable development challenges.

According to the latest statistics, "In Vietnam, every year the forest is lost about 200,000 hectares, of which about 50,000 hectares are due to reclamation for cultivation" (Many authors, 2005; p. 154). Forests are lost, dragging the carpet layer to regulate lost flow, flooding and disasters caused by it. Looking more broadly, "According to the current deforestation rate, with 11 million hectares per year, by 2040 the world will lose between $17 \%$ and 35\% of the 10 million species. In 2040, 20-70 species will be extinct every day" (Many authors, 2005; p. 155). Along with deforestation, the speed of urbanization and industrial development is fast, making nature in our country depleted. Only in 5 years (2001-2005), "the total area of the country's agricultural land acquired for different purposes is about 366,400 hectares, or $3.89 \%$ of the total agricultural land area being used. On average, each year in the above period, there are 73,288 hectares of agricultural land to be recovered" (Vietnam Buddhist Church, 2012; p.3) and most of the land is good. On the other hand, industrial production "hot development" lack of control mechanisms, discharging into the environment many toxic substances polluting water sources, soil, air, food ... turning many places into landfills industry, receiving hazardous waste, creating land desolation, altering landscapes and ecosystems, threatening the survival and development of life. Negative impacts from climate change and environmental pollution are one of the factors that threaten sustainable development in Vietnam, requiring the participation of many sectors and sectors. domestic and foreign organizations and organizations, including activities of domestic and foreign Buddhist organizations.

Compared to other religious organizations, Buddhism is said to be the largest religious organization in Vietnam today. The history of existence and development of Buddhism in Vietnam has been more than 2000 years, has gone through many stages with different ups and downs. Buddhism was spread into Vietnam at first only spontaneously. Later, Buddhism was seized by Vietnamese feudal dynasties (such as Dinh, Tien Le, Ly and Tran periods). Buddhism has long been in the subconscious mind of people, attached to the community activities of the Vietnamese people, a natural attachment not imposed by the government, even if Buddhism is respected as a state religion. The long-term existence of Buddhism in the economic, political and social life has brought significant contributions to culture, thought, economy and politics in the history of Vietnam. Currently, Buddhism is being supported by the Communist Party and the Vietnamese State. As of June 2011, Vietnam has 46,459 monks and nuns, 14,778 worshiping facilities, about 10,000,000 followers who have taken refuge (not to mention tens of millions of people who have feelings and Buddhist beliefs (Thich Gia Quang, 2016).

Since being introduced into Vietnam, Buddhist organizations in Vietnam have quickly attached to the nation in the process of common development. Along with other religious organizations, Vietnamese Buddhism is now actively involved in the areas of social activities, in which the environment and environmental protection are also very concerned issues and uncle important. In terms of awareness, Vietnamese Buddhism always upholds the simple, economical and balanced lifestyle, "thiểu dục tri túc" "less education but gaining much understanding" of Buddhists will contribute to reducing pressure on the environment and natural ecosystems (Nguyen Van Tran, 2013; p.16). Practically, by their methods and methods, Vietnamese Buddhism is every day advocating and propagating in monks and nuns, Buddhists on environmental issues are posing in the modern times that people are facing as well as the must protect the environment as it protects its own life. The current message of environmental protection of Vietnamese Buddhism is the words of Venerable Thich Pho Tue (Thích Phổ Tuệ)- Dharma master of the Vietnam Buddhist Church affirmed: "The world in general and our country in particular are facing many difficulties due to the impacts of climate change, the environment, increasingly exhausted natural resources, increasing global temperatures, droughts and floods. floods, epidemics, tsunamis, earthquakes, sea level rise, ... are disasters that threaten the safety of human life. More than ever, I call on every monk and Buddhist, we need to understand the nature of Buddha's teachings on impermanence, respect for life and the organic relationship between people and nature, to join hands with the social community to protect the social environment and the safety of the earth, it is a practical task to honor the day of our birth to our Đức Từ Phụ" (Thich Pho Tue, 2011). 
Currently, the level of interest and participation of Buddhist religious people in the movements and campaigns of environmental protection organized by the government is increasing. Religious people actively participate in environmental protection activities at worship facilities and residential areas with high rates (74\%). According to statistics from The General Department of Environment (VEA) from 46 provinces and cities nationwide, 67\% of worshiping establishments regularly organize environmental propaganda activities for religious people. Objects of environmental communication in worshiping establishments are mainly religious people. In which the proportion of religious people is Buddhism accounts for 72\% (Tran Linh Chi, Nguyen Song Tung, 2014; pp 117-129). In Buddhist monasteries also regularly organize retreats for Buddhists with rich and diverse content. In particular, the issue of environmental protection is also lectured by dignitaries, propaganda for followers and Buddhists as an important content. Coming to these retreats, devotees and Buddhists will gain knowledge of environmental protection from the point of view of Buddhism, so that they can apply and practice immediately in daily life and encouragement. Encouraging others to join hands in action for the environment. Not only paying attention to the cause of environmental protection, Buddhism also pays attention to the development strategy in Vietnam today. The interest of Buddhism in the strategy of sustainable development in Vietnam today is expressed in many ways such as: an example of how to practice and implement environmentally friendly lifestyles; build and develop religious practice facilities associated with nature and especially pay attention to education and training as one of the fundamental solutions to contribute to sustainable development. It can be said that Buddhist education activities have made positive contributions to society on the basis of Vietnamese human resources in the current period. The world is currently at risk of unsustainable development. In that context, Buddhist education has contributed to solving quite a number of issues posed for sustainable development. On the one hand, the Buddhist educational philosophy has a certain meaning in social sustainable development. On the other hand, Buddhist education itself also has elements of sustainability and there is a adjustment towards sustainable development to meet its role in the social requirements. Different from the compulsory and compulsory education of most monotheistic religions, Buddhism takes good teaching, it is necessary for believers to choose and turn themselves into actions so that they are reasonable and reasonable. That form of education focuses on the process of self-cultivation of mind and nature. It is an education that focuses on practical experience, transforming doctrinal content into concrete action and reality. Educating Buddhism helps people improve their personality, master themselves, and thoroughly understand happiness and suffering. Buddhist education has a certain effect on sustainable development of society. Specifically, Buddhist education has a certain effect on people and subjects of sustainable development. In order to meet the role set for Buddhist education, this religious organization itself has also shifted towards sustainable development. The education system of the Vietnam Buddhist Church today has many similarities with the national education system in general (Doan Minh Huan and Nguyen Quynh Tram, 2014; p.70).

The education of the current Vietnamese Buddhist Church is: primary, intermediate, university and postgraduate. Until 2016, the whole country has 34 Buddhist schools, 3 Buddhist institutes, have been training for over 26,000 monks and nuns (Vietnam Buddhist Education: Traditional and modern, 2016). In general, the role of religion not only contributes to sustainable economic and environmental development, but also in the field of social development in Vietnam today.

Although many important achievements have been achieved, the role of Buddhism in the cause of environmental protection and sustainable development in Vietnam today is also facing many limitations, difficulties and challenges such as problems. era. The development of weapons and science and technology has transformed the life and daily life, including the activities of monks. The transformation of the world, of the era is happening rapidly, but the training of people of Buddhism adapting to these transformations is quite slow... Since then, set out solutions to promote more effectively the role of Buddhism in the cause of environmental protection and sustainable development in Vietnam today such as strengthening activities on propaganda. and raise awareness for all monks and Buddhists about the current cause of environmental protection and sustainable development in Vietnam; Expand the forms of application and practice of Buddhist teachings on environmental protection and sustainable development for all strata of the population; Incorporating the leadership of the Party together with the management role of the State of Vietnam with the leadership and management of the Vietnam Buddhist Church from the central to local levels in raising awareness and effectively implementing the role of Buddhism in the current environmental protection 
and sustainable development in Vietnam, etc.

\section{CONCLUSiON}

Just like many other religions interested in the cause of environmental protection and sustainable development, but for Buddhism, it is even more meaningful when it is the philosophical views in the original Buddhist teachings as well. has mentioned a lot about this issue from the perspective of the world view and the perspective of this religion. Since coming to Vietnam, Buddhism has gradually asserted its role and became a part of Vietnamese culture, joining and contributing greatly to the development of Vietnam. general development of the country. In the current career of environmental protection and sustainable development in Vietnam, through many different practical forms through which Buddhism has also shown its great role. Although there are many limitations and difficulties, even challenges but with the tradition of accompanying the nation, Buddhism has been contributing more to the common development of the country including the protection career. environment and sustainable development.

\section{REFERENCES}

[1] Johnson, D.L., S.H. Ambrose, T.J. Bassett, M.L. Bowen, D.E. Crummey, J.S. Isaacson, D.N. Johnson, P. Lamb, M. Saul, and A.E. Winter-Nelson. 1997. Meanings of environmental terms. Journal of Environmental Quality 26: 581-589.

[2] The International Strategy for Disaster Reduction (March 31, 2004). Accessed June 9, 2010.

[3] Law of Environmental Protection. The National Assembly of the Socialist Republic of Vietnam issued in accordance with Decision No. 55/2014 / QH13 June 23, 2014.

[4] Shaker, R.R. (2015). The spatial distribution of development in Europe and its underlying sustainability correlations. Applied Geography, 63, 304-314.doi.org/10.1016/j.apgeog.2015.07.009 pg305.

[5] Pham Thi Thanh Binh, Sustainable Development in Vietnam: Evaluation criteria and development orientation. Online Finance Magazine, updated on October 12, 2016

[6] The Theory of Causality (Central Business, Bible 115, Bahudhatuka Sutta) - Venerable Thich Minh Chau's translation

[7] Tran Linh Chi, Nguyen Song Tung, 2014, "Environmental communication in religion in Vietnam today". Religious studies, number 01 (127), pp 117-129.

[8] Phương Lập Thiên (2005), "Buddhist philosophy of ecology and modern ecological consciousness", Journal of Research Xuanzang Buddha (Taiwan), period 2, page 135 - 172, Source: http: // www.lieuquanhue.vn, May 13, 2015

[9] Kinh Trung A Ham sutra, Pham Chi A Kinh Vien Hoa sutra, Venerable Thich Minh Chau translated. VNCPHVN published, 1992.

[10] Nguyen Thi Trang, Buddhist thought and its influence on Vietnamese society. http://chuaxaloi.vn/tintuc/tq11-phat-giao-voi-bao-ve-moi-truong/610.html. update 22 August, 2017.

[11] Joanthan Landaw: The story of Shakyamuni Buddha (Liked the Truth and Nature). Religion Publishing House, 2006, p. 167.

[12] (Many authors), 2005, Buddhism in our time, Publisher. Religion.

[13] Pham Cong Nhat, "Ecological ethics in Buddhist philosophy". Phu Yen University Science Journal, No. 15/2017, pp.1-9.

[14] Pham Cong Nhat, "Some issues in ecological philosophy ". Proceedings of 14 th International Conference on Humanities and Social Sciences 2018 (IC-HUSO 2018) 22nd -23rd November 2018, Faculty of Humanities and Social Sciences, Khon Kaen University, Thailand. ISBN (e-book) : 978-616-438-332-6 (https://hs.kku.ac.th/ichuso/Proceeding-ichuso-2018.html) Paper Number: ICHUSO-204, pp.1324-1334

[15] Thich Gia Quang, Statistics of monks and nuns, Buddhists in Vietnam: Theory and practice. Vietnam Buddhist Church (Version online) Updated at 10:20 September 14, 2016

[16] Nguyen Van Tran, "Buddhism with environmental protection in Vietnam”. Journal of Religious Studies, No. 9 (123), 2013, p.16.

[17] Thich Pho Tue (2011), Buddha's Message of 2011 year. http://www.thichchanquang.com/news/Thongc491iep-Phat-c491an-cua-Phap-chu-dien-van-cuaHT-chu-tich-Hc490TS.aspx.

[18] Doan Minh Huan and Nguyen Quynh Tram, "Teaching Buddhism with sustainable development". Religious studies, No. 10 (136), 2014, p.70.

[19] Vietnam Buddhist Church (2012), Proceedings of Buddhist Education Science Workshop: orientation and development. 
[20] Vietnam Buddhist Education: Traditional and modern. Newspaper News onlie, updated on November 16, 2016.https://thuvienhoasen.org/a11554/20-gioi-khong-sat-sinh

[21] http://daibaothapmandalataythien.org/ly-do-va-loi-ich-cua-viec-giu-gin-ngu-gioi-trong-dao-phat

\section{AUTHORS' BIOGRAPHY}

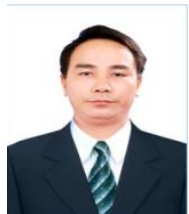

Pham Cong Nhat, Associate Professor, born in 1963 in Vietnam, Doctor of Philosophy, Faculty of Philosophy, University of Social Sciences and Humanities (USSH), Vietnam National University, Hanoi (VNU), Vietnam; Areas of study: culture, education, religion, human development and society, environmental ecology and sustainable development.

Citation: Assoc. Prof. Pham Cong Nhat. "The Role of Buddhism in Environmental Protection and Sustainable Development in Vietnam Today". International Journal of Humanities Social Sciences and Education (IJHSSE), vol. 6, no.5, 2019, pp. 74-82. doi: http://dx.doi.org/10.20431/2349-0381.0605007.

Copyright: () 2019 Authors. This is an open-access article distributed under the terms of the Creative Commons Attribution License, which permits unrestricted use, distribution, and reproduction in any medium, provided the original author and source are credited. 